\section{LA AGRESIVIDAD: FACTOR DE EXCLUSIÓN EN LA ESCUELA}

\section{Mari Sol Sánchez Álvarez, Jilma Alvarado Liscano, \\ Omaira Rosales UPEL-IPB}

Recibido:06-07-06

Aceptado: 07-12-06

\section{RESUMEN}

Esta investigación aborda la temática de Educación para la Paz. Responde a un enfoque cualitativo, de campo, investigación acción participante, de carácter reflexivo, crítico. Su propósito fue el estudio comparativo de la agresividad en tres escuelas del Estado Lara, Venezuela. Se realizó un diagnóstico y se formuló, aplicó y evaluó un Plan de Acción sustentado en la interacción social para minimizar el comportamiento agresivo. El estudio se apoya en Bandura (1981) y Rogers (1984). Los actores fueron 90, organizados en nueve grupos; tres por escuela, conformados por docentes, estudiantes, padres y representantes. Las técnicas de recolección de información fueron la observación participante, la entrevista a profundidad y las notas de campo. Los resultados arrojaron un alto nivel de agresividad en $90 \%$ de los actores. Con la intervención realizada se fortaleció en el educando un desarrollo social justo, equilibrado, humano, para que viva dentro de los valores de solidaridad humana, y mejorar la convivencia de docentes, estudiantes, padres y representantes, dando sentido a sus proyectos de vida.

Palabras claves: estrategias, interacción social, agresividad

\section{AGGRESSIVENESS: EXCLUSIONARY FACTOR AT SCHOOL}

\section{ABSTRACT}

This research focuses on Education for Peace. It is a field-qualitative, participant-action research, with a reflexive, critical orientation. It intends to compare aggressiveness in three schools in Lara state, Venezuela. First, a diagnosis was made. Then, an Action Plan to reduce aggressive behavior based on social interaction was designed, applied and evaluated. The theory supporting the investigation is that of Bandura's Fundamentals (1981) and Rogers (1994). The actors of the research were 90, organized in nine groups, three per school, composed of teachers, students and parents. Participant observation, interview in depth and note-taking were used as data collection techniques. The outcomes expressed high levels of aggressiveness in $90 \%$ of actors. Through the researchers' intervention, a social, fair, balanced and human development on students was reinforced, for them to live in a caring environment, and improve the relationship among teachers, students and parents, making sense to their long term projects.

Keywords: strategies, social interaction, aggressiveness

\section{INTRODUCCIÓN}

La escuela constituye el espacio social que da continuidad a la experiencia de la familia, se puede decir que se trata del primer escenario de carácter general en el cual el niño aprende a ser un sujeto de vida social.

En ese espacio social, especialmente en Educación Básica, el docente de la primera etapa debe dedicarse a cumplir con la altísima responsabilidad de educar y formar, con una actitud abierta al cambio, capaz de interpretar y reflexionar las condiciones reales del medio y la comunidad donde se desenvuelve, actuando asertivamente y desarrollando en los educandos comportamientos adecuados que le permitan su desarrollo integral.

En tal sentido, el docente en su función orientadora podría utilizar estrategias de Interacción Social para minimizar los comportamientos agresivos que se presenten, que le permitan atender al educando de manera holística, formarlo como un individuo solidario, respetuoso, responsable, critico, reflexivo, que valore a los demás y sea capaz de establecer con facilidad las relaciones interpersonales. 
Es por ello, que la presente investigación tuvo como propósito el estudio y comprensión del comportamiento agresivo en los actores de tres escuelas de educación rural básica, a fin de minimizarlo utilizando la Interacción Social como estrategia de aprendizaje.

\section{CONTEXTO DE LA INVESTIGACIÓN}

Las escuelas involucradas, "Emperatriz de Aguero“, "Los Cerritos” y "Cerro Pelòn”, son instituciones educativas rurales pertenecientes a la Parroquia "Cabo José Bernardo Dorante", asentada en la depresión del Valle de Quíbor, capital del Municipio Jiménez, Estado Lara.

Los elementos que permiten caracterizar a las comunidades, son entre otros: desde el punto de vista educativo, existe alto porcentaje de analfabetismo, la mayoría de los habitantes no culminó la Educación Primaria. Desde el punto de vista económico, las familias viven del trabajo que realizan en las diferentes haciendas que bordean la comunidad, donde laboran como jornaleros por día. Desde el punto de vista afectivo, existe un alto porcentaje de padres y representantes que expresan una baja autoestima, no asumen sus responsabilidades y dejan a la escuela el fortalecimiento de valores en sus hijos. Hombres y mujeres maltratados verbal, física y psicológicamente en su niñez, ofrecen a sus hijos el mismo trato.

En cuanto a los docentes, tenemos un alto grupo de docentes resistentes al cambio, con creencias arraigadas sobre el liderazgo autocrático, que gritan, golpean y maltratan verbal, física y psicológicamente a sus alumnos, que no emplean estrategias innovadoras y creativas para facilitar el trabajo en el aula, que incumplen con los acuerdos establecidos, el horario, la planificación, las comisiones de trabajo, que evaden o dificultan la comunicación y que no atiende los aspectos acordados y asumidos en los Consejos Docentes.

En contraste, es común encontrar niños alegres, creativos, dispuestos a participar en actividades y a aprender, algunos con muchas destrezas y habilidades para el arte (tanto estético como musical), responsables e interesados en sus estudios, que presentan grandes deficiencias en lecto-escritura y en las operaciones básicas (suma, resta, multiplicación y división), de escasos recursos económicos, con marcadas carencias afectivas, pérdida de valores y una conducta agresiva y violenta.

\section{EL PROBLEMA DE ESTUDIO}

Los testimonios aportados por los actores del estudio, especialmente niños, padres y representantes, habitantes de las comunidades "La Vigía”, "El Cerrito" y “Cerro Pelón” surgidos de los encuentros realizados en las Unidades Educativas Nacionales "Emperatriz de Aguero” y Cerro Pelón el día sábado 14-02-04 y “Los Cerritos”, el 2505-04, señalan las siguientes aseveraciones: "La relación en mi hogar con mis hijos es muy mala. "Me maltrataron y yo los maltrato físico y verbalmente;"Mi relación con mis padres fue muy mal ellos no me dieron amor de padre a hijo pero a pesar de todo les agradezco mi vida".

Otros testimonios obtenidos de entrevistas a niños y niñas, confirman la problemática presente:."Quiero una familia que me comprenda que no me maltraten verbal ni físicamente y quiero que en mi familia halla comunicación y padres amorosos que nos ayuden"; "La relación con mis padres ha sido injusta porque ellos me regañan y me pegaban"; "nosotros queremos una familia que nos den amor, ternura, que nos aconsejen cuando tenemos un problema, que nos comprendan, que nos entiendan sin groserías ni maltratos, que sea unida y que no peleen".

Sólo el $8 \%$ de los testimonios restante reflejó un trato diferente: "la relación con mi madre es chévere aunque me regaña y me pega cuando me porto mal"; "mi relación con mis padres es buena y mala"; " se la pasan todo el día bebiendo anís, penca y ron parejo"; mamá me quiere mucho se porta muy bien conmigo pero cuando me porto mal me castiga 
o me pega. Yo quiero mucho a mi mamá y a mi padrastro no me gusta que me regañe ni me pegue.

Las expresiones verbales agresivas en docentes son las más llamativas, ya que se exponen a través de gritos y de palabras indecentes o no adecuadas. Las siguientes expresiones de niños y niñas son evidencia de ello: "No queremos que griten en los salones, ni digan muchas groserías"; la relación con mis maestros siempre fue muy buena, aunque gritan mucho"; "quiero que el docente sea amoroso, comprensivo con los alumnos y el representante y no nos trate mal"

Un porcentaje minoritario de niños y niñas indicaron opiniones contrarias y sólo manifestaron malestar en el hogar: "cuando estoy en clase es que me siento en mi sitio en cambio en mi casa no"; "hay buena comunicación entre mis compañeros, profesores y miembros de la institución”

La problemática descrita fue corroborada al revisar las actas elaboradas en la escuela cada vez que ocurría el incidente correspondiente. En las mismas se encuentran descritos casos de docentes, padres, representantes y estudiantes con comportamientos agresivos.

Partiendo de los argumentos presentados surgió la inquietud de efectuar este estudio, el cual tuvo como norte dar respuesta a las siguientes preguntas de investigación:

¿Será posible determinar las causas que originan la agresividad en los educandos de las Unidades Educativas objeto de estudio?; ¿Se podrán precisar los tipos de agresividad presentes en los actores? ¿Influye el entorno y el modelado en el aprendizaje de comportamientos agresivos? ¿Se podrá minimizar la agresividad de niños, niñas y adultos?; ¿La aplicación de estrategias de interacción social permitirán minimizar la presencia de conductas agresivas”?.

\section{Objetivos de la Investigación}

\section{General}

Validar un conjunto de estrategias de interacción social orientadas a minimizar el comportamiento agresivo que afecta el proceso enseñanzaaprendizaje en los educandos de la Primera Etapa de Educación Básica.

\section{Especificos}

Diagnosticar las causas y tipos de comportamientos agresivos presentes en los actores sociales de las Unidades Educativas "Emperatriz de Agüero", “Cerro Pelón” y los “Cerritos”, del Municipio Jiménez, del Estado Lara.

Establecer las necesidades de capacitación sobre comportamientos agresivos, en los docentes de la Primera etapa de Educación Básica de las tres escuelas.

Determinar las necesidades educativas sobre comportamientos agresivos en padres y representantes de educandos de la Primera etapa.

Programar el conjunto de estrategias de interacción social que permitan minimizar los comportamientos agresivos presentes en los actores.

Aplicar el conjunto de estrategias diseñadas durante un lapso de seis meses.

Evaluar la efectividad del conjunto de estrategias aplicadas sobre el nivel de agresividad detectado.

BASES TEÓRICAS

Teorías que sustentan el estudio 
Este trabajo de investigación considera los aportes de las teorías de Aprendizaje Social de Albert Bandura (1981) y la Humanística, propuesta por Carl Rogers (1984).

Teoría de Aprendizaje Social. Bandura A y otros (1981), señala que las pautas de comportamiento pueden aprenderse por propia experiencia y mediante la observación de los comportamientos de otras personas. Para este autor, los comportamientos dependen de una serie de factores ambientales (estímulos, refuerzos y castigos), y personales (creencias, pensamientos, expectativas), que interactúan entre sí.

En sus investigaciones sobre la agresividad, expone que el hecho de ver a otra persona comportándose de forma agresiva puede incrementar la agresividad en los niños, quienes no se limitan solamente a una mera conducta imitativa sino que inventan nuevas formas de agresión. Para este teórico, la conducta agresiva se aprende gracias al modelado: observando e imitando a otras personas que actúan como modelos.

Teoría Humanística. Rogers (1984), concibe el ser humano en constante interacción con el ambiente e indica que la naturaleza humana es constructiva. Este autor plantea que existen situaciones enajenantes que pueden bloquear el desarrollo constructivo del ser humano, pero incluso en estos ambientes adversos, las personas conservan su tendencia hacia el desarrollo integral. La motivación del ser humano es su autorrealización, el desarrollo de sus potencialidades. También indica que la familia es de gran influencia en la búsqueda de acciones positivas y que los requerimientos de amor de las personas son significativos en su vida.

La filosofía humanística no niega la existencia de impulsos agresivos, los mira como parte o elemento del hombre que surgen como producto de la enajenación en la cual el ser humano pierde contacto consigo mismo, se cierra y adopta actitudes defensivas llevándolo a la incongruencia y a la contradicción. Al respecto, el investigador hace referencia al cambio de comportamiento que puede producirse a través de la identificación, el análisis y la reflexión del problema que lo afecta y del uso de una estrategia adecuada, la cual constituye el elemento más importante para modificarla.

Rogers recomienda un aprendizaje vivencial donde los educandos puedan percibir y transferir hechos de la vida cotidiana. Este aprendizaje permite que el alumno reflexione sobre su comportamiento ya que toda persona tiene un potencial para cambiar cuando toma conciencia de la situación que lo afecta y confronta el problema en forma eficiente.

Desde estas perspectivas teóricas, la indagación se propuso revisar cómo los individuos que pertenecen a una determinada cultura llegan a incorporar y controlar el sistema de signos que la caracterizan y cómo éstos llegan a ser internalizados a través de sus comportamientos.

\section{Perfil del niño (a) Agresor}

Según Smit (1990), los niños (as) agresores se caracterizan por:

1. Una situación social negativa, siendo incluso rechazados por una parte importante de sus compañeros, pero están menos aislados que las victimas, y tienen algunos amigos, que les siguen en su conducta violenta.

2. Una acentuada tendencia a la violencia, a dominar a los demás, al abuso de su fuerza (suelen ser físicamente más fuertes que los demás). Son bastantes impulsivos, con escasas habilidades sociales, baja tolerancia a la frustración, dificultad para cumplir normas, relaciones negativas con los adultos y bajo rendimiento: problemas que se incrementan con la edad.

3. Su capacidad de autocrítica suele ser nula; en relación a lo cual cabe considerar el hecho observado en varias investigaciones, al intentar evaluar la autoestima de los agresores, y encontrarla media o incluso alta. 
4. Ausencia de una relación afectiva, cálida y segura por parte de los padres, y especialmente por parte de la madre, que manifiesta actitudes negativas y/o escasas disponibilidad para atender al niño; y fuertes dificultades para enseñarles a respetar limites, combinando la permisibilidad ante conductas antisociales con el frecuente empleo de métodos coercitivos autoritarios, utilizando en muchos casos el castigo físico.

5. La situación de agresor es mucho mas frecuente entre los chicos que entre las chicas, y suele mantenerse muy estable, o incrementarse a lo largo del tiempo; especialmente en la preadolescencia.

6. Aunque el grupo de agresores es menos heterogéneo que el de victimas, la mayoría de las investigaciones diferencian entre los agresores activos, los que inician la agresión y la dirigen, de los agresores pasivos, que les siguen, les refuerzan y les animan, y que parecen caracterizarse por problemas similares a los anteriormente mencionados pero en menor grado.

Perez (1993) destaca que existen factores externos que influyen en el comportamiento agresivo del niño, como lo es el factor sociocultural y que, dentro de éste, se encuentran los siguientes elementos: a) la familia que es el modelo fundamental y determinante de la conducta a seguir por el niño; b) la disciplina a la cual se somete al niño, demostrando que una actitud poco exigente como la hostil, por parte de los padres tiende a fomentar el comportamiento agresivo; c) la incongruencia de los padres al castigar o ignorar una conducta irregular; $\mathrm{y}$, d) las relaciones deterioradas entre los propios padres, provocando tensiones que inducen al niño a comportarse en forma agresiva.

Igualmente, este autor menciona que en el comportamiento agresivo también intervienen factores orgánicos, de tipo hormonal, mecanismos cerebrales, estado de mala nutrición y problemas de salud específicos.

Pinzón (1996) indica que existen algunas estrategias que permiten canalizar el comportamiento agresivo en el niño. Recomienda aplicar como técnica de disciplina el razonamiento y la desaprobación de dicha conducta. Esto facilita desarrollar en los niños conciencias sólidas y lo ayuden a apaciguar la agresividad. Hokanson (citado por Dorsch, (1994), establece que el apaciguamiento de la agresividad puede producirse mediante un comportamiento amistoso reduciendo los estímulos desagradables en el niño.

Rojas (1996), reseña que la mejor manera de reducir los comportamientos agresivos en el niño en la escuela es aplicando programas más efectivos en edad temprana (4 a 12 años), donde el docente pueda desarrollar la compasión, el desinterés, el sentido de la autocrítica y la empatía.

Goleman (1996), Sequera (2000), Bisquerrea (2000), y Gessem (2001), concluyen, producto de sus estudios afirmando que existe un intimo lazo entre emociones y comportamiento agresivo. El entorno donde se desenvuelven y las personas que los rodean, juegan un papel de vital importancia en la formación de la conducta de los niños y niñas.

\section{Estrategias de Interacción Social}

Diferentes investigaciones han desarrollado estrategias de interacción o de mediación social contra la agresividad escolar, entre ellas se destacan las siguientes:

Círculos de calidad, (Smith 1993), encuentro donde un grupo de personas se reúnen regularmente, se interesan en identificar, analizar y resolver problemas comunes. Son muy eficaces para cualquier situación en la que se demande la motivación de los alumnos.

Ayuda entre iguales, (Ortega, del Rey y Mora, 2001), consiste en que un grupo de niños/as actúen como consejeros y ayudantes de niños/ as que están en proceso de sufrir o haber sufrido malos tratos o abusos. Su finalidad es que los niños/ as encuentren, en la conversación y 
apoyo, una solución o reflexión sobre su problema.

Desarrollo de la asertividad para victimas, (Ortega, 1998), estriba en emular ejercicios de habilidades sociales que posibiliten que la victima realice la secuencia completa de estar en una situación en la que debe tomar una decisión, y pueda observar que los resultados son reforzadores de la autoestima.

Desarrollo de la empatía para agresores, (Ortega, 1998), son procesos educativos que restablecen la sensibilidad emocional y afectiva en niños/ as que han vivido en ambientes de agresividad o poco afectivos.

\section{METODOLOGÍA}

Este estudio se enmarcó en la modalidad de investigación de campo y se desarrolló en las Unidades educativas Nacionales "La Vigía", "Cerro Pelón” y "Los Cerritos”, del Municipio Jiménez, Estado Lara. Por su naturaleza, el diseño tiene carácter eminentemente cualitativo.

El tipo de investigación con el cual se abordó la realidad fue la Investigación Acción Participante. Las variables nominales en estudio fueron las estrategias de interacción social y los comportamientos agresivos de los actores. Para estudiar estas variables se investigó el comportamiento humano de los actores, concebido como lo que ellos dicen, hacen, sienten y piensan con el fin de caracterizarlo y describirlo hasta llegar a acordar un conjunto de estrategias de interacción social, para minimizar los comportamientos agresivos encontrados, reflexionar sobre los mismos y formular explicaciones teóricas acerca de las causas y consecuencias que guiaban sus acciones.

\section{Actores de la Investigación}

Los participantes en este estudio fueron los actores de las Unidades Educativas Nacionales antes señaladas. La muestra fue conformada por los docentes, alumnos padres y representantes de la primera etapa de Educación Básica, para un total de nueve grupos (3 por escuela) y 90 actores. Dicha selección se sustentó en los siguientes criterios: disposición a participar, haber tenido comportamientos agresivos y no haber sido sometidos a proceso de mediación.

\section{Técnicas e Instrumentos de Recolección de Información}

Las técnicas de recolección de información utilizadas fueron la observación participante, la entrevista a profundidad y el registro de notas.

La observación participante sirvió para obtener de ellos la definición de la realidad y los constructos con los que organizan su mundo, así como captar sus comportamientos en las diferentes situaciones que se desarrollaron durante la investigación. La entrevista a profundidad permitió conocer la forma de pensar, actuar y sentir de los entrevistados. A través de ella se llegó a descubrir acontecimientos y dimensiones subjetivas de las personas tales como: creencias, pensamientos y valores.

Las notas de campo facilitaron el registro inmediato de los incidentes observados de manera precisa, minuciosa sin omitir detalles, $\mathrm{y}$ en diversos escenarios.

\section{Validez y Confiabilidad de la investigación}

A fin de garantizar la validez de la información recabada, se utilizó la técnica de triangulación de fuentes, la cual permitió confrontar, corroborar y cruzar los aportes dados por los diferentes actores de la investigación.

La confiabilidad interna estuvo dada por el nivel de consenso que se logró entre los diferentes observadores de la realidad en estudio (Investigadora, tutora, docentes y colaboradores). 
Para reducir las amenazas sobre la confiabilidad externa, se utilizaron categorías descriptivas lo más concretas y precisas posibles.

\section{Análisis de la Información}

Para facilitar el análisis y presentación de la información obtenida durante los diferentes momentos de la investigación, se registraron las categorías, testimonios y demás datos derivados de las diferentes actividades.

\section{Etapas de la Investigación}

Esta investigación fue desarrollada siguiendo las etapas que se presentan en la gráfica siguiente y se describen posteriormente:

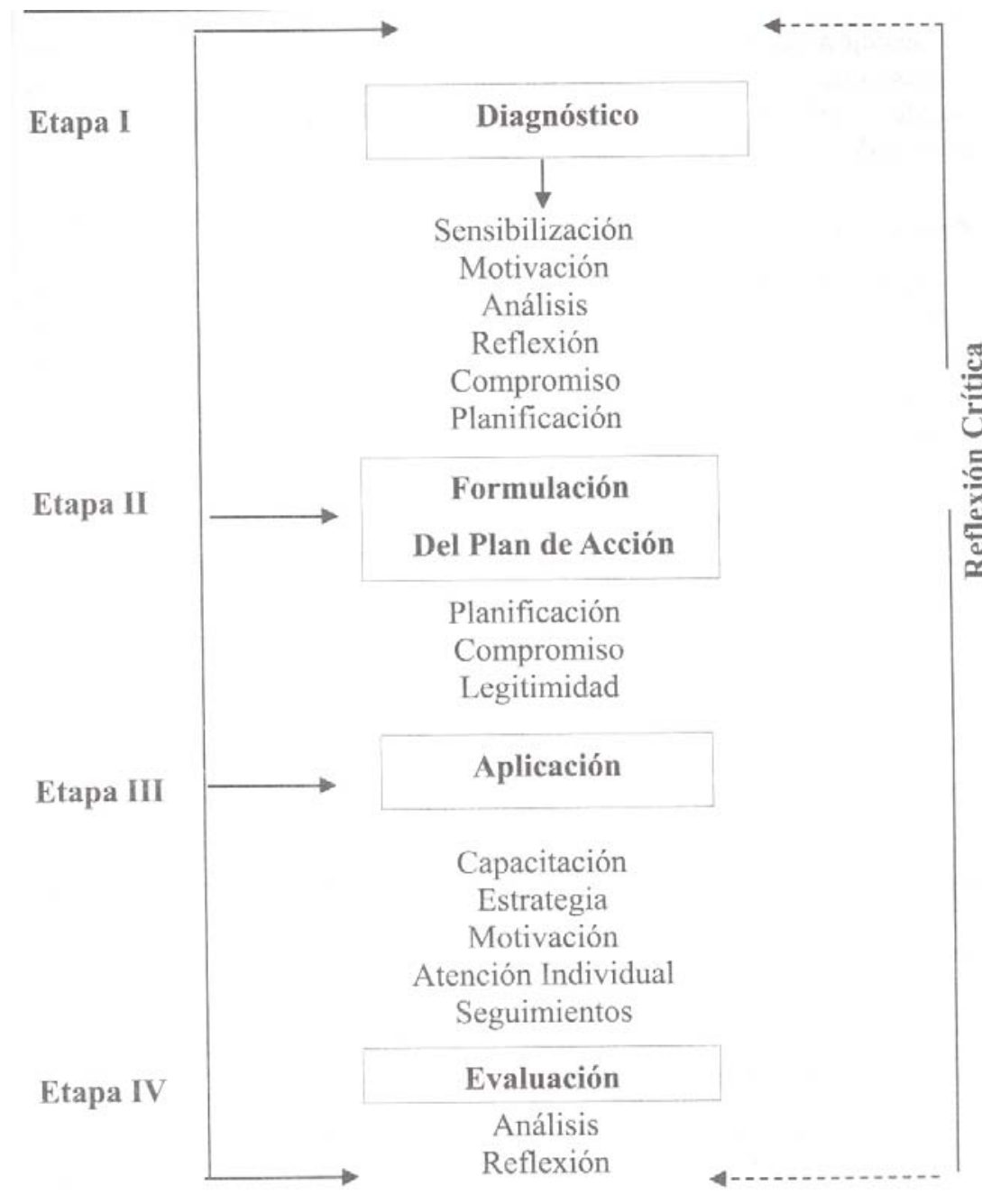

Grafico 1 . Etapas, fases y procedimientos de la investigación. 


\section{Etapa I. Diagnóstico.}

La etapa diagnóstica se mantuvo durante todo el proceso de la investigación que duró dos años e incluyó la observación permanente y la recolección de información durante las diferentes jornadas de trabajo. Este se inicia en los Consejo Docente No 1 del año escolar 2003-2004, donde se solicitó el permiso a directivos y docentes para llevar a cabo el trabajo de investigación.

\section{Etapa II. Formulación del Plan de Acción}

Luego del análisis de la información recabada en los encuentros “Corazones y manos unidos por la convivencia y paz”, se realizó una jornada de reflexión con el fin de diseñar, en conjunto, un plan de acción que permitiera atender las necesidades e intereses de los actores de la investigación. Dicho plan se orientó a minimizar los comportamientos agresivos y mejorar la convivencia en los diferentes ámbitos del quehacer educativo.

El primer paso fue elaborar un informe descriptivo con toda la información obtenida sobre la situación que presentaban cada una de las escuelas. El segundo paso fue darlo a conocer ante los actores, en una reunión de trabajo convocada para tal fin. Su contenido, fue leído, analizado y reflexionado, de forma individual y grupal, por los actores y los resultados que se derivaron del análisis presentado por representantes de los grupos de trabajo, en una plenaria.

Las reflexiones y sugerencias emanadas del trabajo grupal, fueron el soporte para la estructuración del plan de acción final. A sugerencia de los grupos y para dar mayor formalidad al trabajo y lograr el compromiso de los actores, fue redactado un documento (Acta Compromiso), el cual fue firmado por todos los asistentes.
Al final de la actividad, las reflexiones más importantes emitidas por los participantes fueron las siguientes:

1.- La educación basada únicamente en la transmisión de conocimientos, hace una enseñanza rutinaria; convirtiendo a los alumnos en seres pasivos sin creatividad, ni participación sin enseñarles a pensar críticamente, ni a razonar ni a crecer como persona.

2.- La realidad actual que nos enfrenta a lo desconocido, a un cambio de información, de conocimientos, de avances tecnológicos y científicos acelerado, demanda de la producción de conocimientos de alta calidad y competitividad.

3.- Las Unidades Educativas Nacionales Emperatriz de Aguero“, “El Cerrito” y “Cerro Pelón “, deben buscar transformar el esquema escolar para generar calidad y dar sentido de comunidad, expresando esta necesidad en los pilares filosóficos estadales y nacionales como son: el ser, el hacer, conocer y convivir. Las reflexiones relativas a los docentes exigen que estos se conviertan en profesionales creativos que guíen a los estudiantes a lo largo de la vida, incorporando a los padres y representantes, entes gubernamentales y comunidad en general en la formación de los mismos.

En ese orden de ideas, la Jornada de trabajo cumplió su cometido, ya que cumplió con su propósito motivar a los diferentes actores del quehacer educativo para que reflexionaran y analizaran sus comportamientos, dentro y fuera de la institución, tomando como elementos orientadores el diagnóstico generado por los investigadores, 
así como los dos diagnósticos presentados por los entes gubernamentales Prevención del Delito y la LOPNA.

De igual forma, plantearon como objetivo: Propiciar compromisos individuales con los actores de la investigación para lograr la participación en las diversas actividades planificadas.

Los resultados obtenidos permiten afirmar que tanto el propósito como los objetivos planteados se cumplieron y dieron como resultados la sensibilización de los actores hacia el trabajo a emprender en la escuela y la comunidad.

\section{Fase III. Ejecución del Plan de Acción}

La puesta en práctica del plan de acción permitió atender las dimensiones y categorías que emergieron durante la investigación. El mismo incluyó los objetivos, metas, estrategias, tiempo, responsables y la evaluación de los avances o logros del grupo.

A partir de entonces comenzamos a trabajar sobre las primeras actividades consideradas en las reuniones de análisis y reflexión, tomando siempre en cuenta las fortalezas y oportunidades presentes y evitando, en lo posible, la magnificación de las debilidades y limitaciones que presentaban los grupos de actores.

Lograr el consenso, resultó fácil en la mayor parte de las estrategias puesto que habían sido sugeridas por ellos mismos. Cuando surgió algún caso en que no se daba dicho acuerdo, el grupo proponía que se explicara que parte de las actividades cambiarían para que también fuera aceptada por ellos. Si dicha sugerencia era admitida por el resto del grupo, entonces era aprobada.

La incorporación de representantes de los organismos de Prevención del delito y del Consejo de Protección al niño, niña y adolescente, facilitaron el establecimiento de una alianza con estas instituciones, lo que permitió fortalecer el diagnóstico, las acciones, las orientaciones y el compromiso de colaborar en la búsqueda de soluciones. De igual forma, estimuló la formulación de proyectos, a los cuales se incorporaron los padres, alumnos y comunidad en general.

De esta situación se aprendió que la llegada de estos organismos a las comunidades representan oportunidades y no amenazas, en donde los actores tienen la posibilidad de recibir educación y asesoramiento sobre diversos temas, de compartir inquietudes, necesidades, problemas y de buscar soluciones. En este caso, las situaciones planteadas fueron atendidas en su mayoría y otras están en vías de solución.

La celebración de las diferentes efemérides fueron dramatizadas y presentadas por los niños en el patio principal de la escuela. En dichas actividades, se incluyeron principalmente los niños que presentaban el problema de comportamiento agresivo, quienes se mostraron muy complacidos y cooperativos, pero sobre todo demostraron comportamientos diferentes.

Dentro de las actividades especiales que se realizaron en la casa comunal con el fin de integrar el mayor número de personas, estuvo la celebración del día de las madres y del padre Todos fueron muy 
receptivos, participativos y responsables. Además se tomó en cuenta la motivación creatividad e iniciativa en los actores para asumir su participación en el proceso.

Cabe destacar que fueron pocos los padres que asistieron a la celebración del “Día del Padre”, sin embargo los que asistieron una vez concluida la actividad nos felicitaron y manifestaron: "esto es la primera vez que se hace, cuanto disfrutamos, el año entrante lo organizamos mejor"

Una de las actividades de mayor impacto fue la organización del festival folklórico-cultural de la escuela y la comunidad, el cual se llevó a cabo el día 30 de Junio de 2004.Cabe destacar que el acto fue muy emotivo y contó con la asistencia de todo el personal de las escuelas y de las comunidades.

En la actividad seleccionada y desarrollada para celebrar de la semana de la conservación, fue elaborado un semillero del árbol Nim, especie que se adapta a la geografía de la zona. Para ello, fueron incorporados los alumnos de la muestra seleccionada, con quienes se intercambió información teórica y práctica sobre el trabajo que realizaríamos, las normas a seguir y el sitio donde sería elaborado el semillero.

Para la atención del área académica fueron incorporados por los docentes diferentes estrategias de enseñanza y de aprendizaje tales como: cuentos, canciones, pinta cuentos, dramatizaciones y paseos; de igual manera se atendieron los alumnos con materias pendientes; y, se dedicó un tiempo importante para la enseñanza y el aprendizaje de deberes y derechos, insistiendo en el reforzamiento del amor, del respeto, la amistad. A fin de preservar la disciplina, incorporaron la técnica del recreo pedagógico.

También fueron publicadas las normas de comportamiento social en el comedor, biblioteca y aulas. Cabe destacar que las mismas fueron elaboradas por los propios alumnos, quienes las ilustraron con dibujos alusivos al tema tratado

A través de los círculos de acción docente se logró que los docentes incorporaran la planificaron a su labor diaria y capacitarlos en diferentes aspectos, tales como: evaluación cualitativa, uso del cuaderno historial, estrategias basadas en valores, dinámicas para controlar y minimizar el comportamiento agresivo de estudiantes. También se logró la incorporación de los padres a la elaboración de los PPA.

En el área comunitaria, se trabajó con los padres, representantes y demás integrantes de los proyectos sociales que se ejecutan en las tres comunidades, tales como Vuelvan Caras y Plan Robinson, quienes colaboraron en el desarrollo de los mismos. También fueron ejecutadas actividades extraescolares como: encuentros deportivos, XXIII Posta en honor a la Virgen de Altagracia, Patrona de la zona. De igual manera, se realizaron gestiones conjuntas de docentes, Junta de vecinos y padres y representantes, ante el organismo gubernamental Mariología del estado Lara, lográndose la asignación de dos dinamos para el bombeo del agua, uno de los cuales fue ubicado para atender las necesidades de abastecimiento de agua de la institución "Emperatriz de Agüero" y el otro, para abastecer el centro de salud de la comunidad "La Vigía”. 
Para atender el área administrativa, se asignaron dos docentes, por escuela, como representantes ante el Consejo de Protección del Niño y del Adolescente, se canalizó la discusión de los reglamentos internos de las instituciones, para lo cual se nombraron comisiones de trabajo que permitieron el logro de lo planificado por el personal técnicoadministrativo.

En lo referente a los objetivos planteados, fueron cumplidos ya que se logró ejecutar y evaluar las estrategias propuestas e incorporar a los docentes, alumnos, representantes y familias, a las diferentes actividades planificadas.

Durante el análisis, discusión y evaluación del Plan de Acción, se observó que el aprendizaje individual y organizacional es un proceso lento y de largo alcance. Sobre este aspecto, la reflexión colectiva indicó que se debe estar consciente que la realización de un conjunto de actividades remediales aisladas son insuficientes para conseguir cambios definitivos en los alumnos y demás actores del proceso educativo, dadas las presiones sociales en las que se encuentran inmersos.

Sin embargo, cabe resaltar que en la medida en que se va actuando y se van produciendo los cambios esperados, el trabajo desarrollado en la escuela incide en el estilo de vida de los actores y en el clima de la escuela y la comunidad.

Concluida la reflexión crítica acerca de la práctica educativa puesta en práctica por los docentes en las tres instituciones escolares, se puede concluir que el proceso de enseñanza - aprendizaje debe estar dirigido a la formulación de un ideal de vida y de sociedad declarado por los estudiantes, los docentes, los padres y representantes.

Los niños y niñas que presentan problemas de comportamiento, requieren de un docente que les facilite la revisión y avance de su actuación individual y social, sobre la base de discusiones productivas, diálogos, reflexiones e intercambio de opiniones. De esta forma, tomarán conciencia de sus propias diferencias y la de aquellos que los rodean. Una de las grandes tareas que los docentes tienen es enseñar estos niños y niñas a amarse a sí mismos, a respetarse; sólo así podrán valorarse y aprender a querer y respetar a los demás.

Otro aspecto importante a ser considerado por los docentes son los padres y representantes, los cuales deben ser incorporados al trabajo del aula. Al hacerlo, se podrá identificar con mayor facilidad los factores causantes o estimuladores de comportamientos inadecuados en los alumnos y desarrollar planes de trabajo conjuntos, que estimulen aprendizajes basados en la cooperación, en oposición con aquellos fundamentados en competencias desleales para ver quien es el mejor.

Los espacios de reflexión en la escuela, fueron considerados como una estrategia que ayuda a generar nuevos conocimientos y a mejorar el compromiso de los actores y la institución escolar, asumida como centro de socialización y formación de individuos aptos para vivir en sociedad. Una escuela comprometida con la paz y la democracia, reforzará comportamientos y estimulará la formación de familias democráticas y de buen trato, aportando así ciudadanas y ciudadanos responsables y comprometidos con su comunidad y el país.

\section{Etapa IV. Evaluación y Reflexión permanente}

Fue decisión del grupo incluir jornadas de reflexión y evaluación permanentes. De esta experiencia se aprendió que la reflexión es un proceso que permite generar ideas basadas en el análisis de nuestras 
acciones para reformular las actividades en aquellas situaciones que requieren cambios.

\section{RESULTADOS}

El Cuadro 1, resume las formas de comportamientos agresivos encontrados en los actores de las escuelas.

\section{actores}

Cuadro 1 Tipos de comportamiento agresivos por grupo de

\begin{tabular}{|c|c|c|c|}
\hline & Docentes & Estudiantes & $\begin{array}{c}\text { Padres y } \\
\text { Representantes }\end{array}$ \\
\hline Verbales & $\begin{array}{l}\text { Gritos, palabras } \\
\text { obscenas, tono de voz } \\
\text { muy alto, ofensas. }\end{array}$ & $\begin{array}{l}\text { Gritan, } \quad \text { palabras } \\
\text { obscenas, burlas, } \\
\text { sobrenombres, } \\
\text { discuten, gestos } \\
\text { despectivos. }\end{array}$ & $\begin{array}{l}\text { Gritos, palabras obsce- } \\
\text { nas, ofensas, insultos, } \\
\text { sobrenombres, discusio- } \\
\text { nes, gestos despectivos. }\end{array}$ \\
\hline Físicas & $\begin{array}{l}\text { Jalón de orejas, pelo, } \\
\text { tiran borrador, } \\
\text { empujones, rasguños. }\end{array}$ & $\begin{array}{l}\text { Pellizcan y halan el } \\
\text { cabello, dañan, } \\
\text { objetos de la } \\
\text { institución y de sus } \\
\text { compañeros, } \\
\begin{array}{l}\text { hurtos, riñas } \\
\text { rebeldes. }\end{array}\end{array}$ & $\begin{array}{l}\text { Golpes, quemaduras, } \\
\text { rasguños, dañan objetos, } \\
\text { riñas. }\end{array}$ \\
\hline Psicológicas & $\begin{array}{l}\text { Amenazas (no van al } \\
\text { recreo, dirección), } \\
\text { aislamiento, insultos, } \\
\text { comparaciones, falta de } \\
\text { normas y disciplinas, } \\
\text { autoritario, indiferencia, } \\
\text { ignorancia, rechazo. }\end{array}$ & $\begin{array}{l}\text { Amenazan, } \\
\text { sobrenombres, } \\
\text { aislamiento, } \\
\text { ataques en grupo, } \\
\text { burlas, rechazo, } \\
\text { desorden. }\end{array}$ & 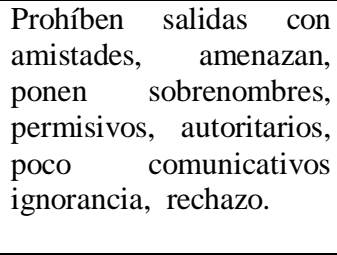 \\
\hline
\end{tabular}

Seguidamente , el cuadro 2, incluye testimonios de los diferentes actores sobre las causas y consecuencias del maltrato, así como las actividades remediales acordadas para atender la situación encontrada. 
Cuadro 2. Testimonios expresados por los actores sobre causas del maltrato, consecuencias y actividades remediales

\begin{tabular}{|c|c|c|c|c|c|c|c|c|c|}
\hline \multirow{2}{*}{ Escuela } & \multicolumn{3}{|l|}{ Escuela A } & \multicolumn{3}{|l|}{ Escuela B } & \multicolumn{3}{|l|}{ Escuela C } \\
\hline & Causas & Consecuencias & Actividades & Causas & Consecuencias & Actividades & Causas & $\begin{array}{c}\text { Consecuenci } \\
\text { as }\end{array}$ & Actividades \\
\hline Estudiantes & 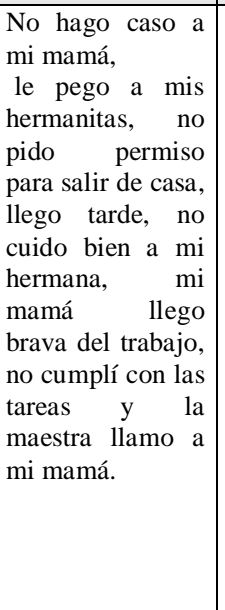 & 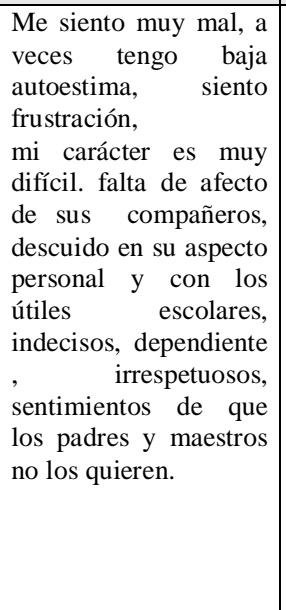 & 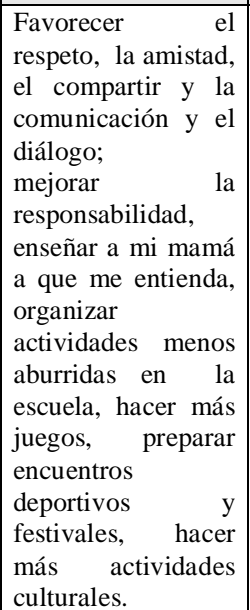 & $\begin{array}{l}\text { Saco malas notas, le } \\
\text { pego a mis } \\
\text { hermanos. } \\
\text { No pido permiso } \\
\text { para salir de casa, } \\
\text { no hago caso a mi } \\
\text { mamá, le respondo } \\
\text { mal a mi mamá, } \\
\text { me hace falta mi } \\
\text { papá. Mi mamá y } \\
\text { mi papá siempre } \\
\text { pelean cuando se le } \\
\text { pierde dinero a mi } \\
\text { mamá. }\end{array}$ & \begin{tabular}{|l} 
Me dan rabia los \\
adultos, me siento \\
frustrado, no me \\
dejan hacer lo que \\
me gusta \\
Niños cohibidos, \\
jóvenes y adultos \\
agresores \\
Maridos violen-tos, \\
familias destruidas, \\
hermanos \\
enemistados, \\
hombres y mujeres \\
agresores.
\end{tabular} & \begin{tabular}{|l} 
Cursos para que \\
mi mamá no me \\
maltrate \\
\\
Organizar más \\
actividades \\
divertidas en la \\
escuela. \\
Talleres sobre \\
maltrato rel \\
niñor Realizar \\
más actividades \\
deportivas y \\
festivales r \\
culturales en la \\
comunidad, \\
talleres para que \\
nos unamos más.
\end{tabular} & 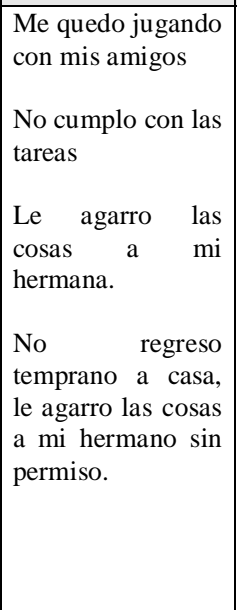 & $\begin{array}{l}\text { Niños } \\
\text { agresivos y } \\
\text { agresores } \\
\text { Niños y niñas } \\
\text { temerosos y } \\
\text { tímidos, } \\
\text { hogares } \\
\text { desarticulados } \\
\text { hombres } \\
\text { violentos, } \\
\text { peleas } \\
\text { familiares y } \\
\text { en la escuela, } \\
\text { Enfrenta- } \\
\text { mientos en la } \\
\text { comunidad }\end{array}$ & $\begin{array}{l}\text { Fomentar valores, fortalecer la } \\
\text { autoestima, favorecer el } \\
\text { respeto, amistad, el diálogo, la } \\
\text { responsabilidad, preparar } \\
\text { reuniones familiares, enseñar } \\
\text { a querer y respetar, organizar } \\
\text { fiestas, ser más cariñosos, } \\
\text { tratarnos mejor, que los } \\
\text { maestros hagan más } \\
\text { actividades que nos guste, no } \\
\text { ponernos tantas copias y } \\
\text { hacernos dictados y cuentas, } \\
\text { no ponernos tantas cuentas y } \\
\text { planas en la pizarra, eso nos } \\
\text { aburre. }\end{array}$ \\
\hline Docentes & 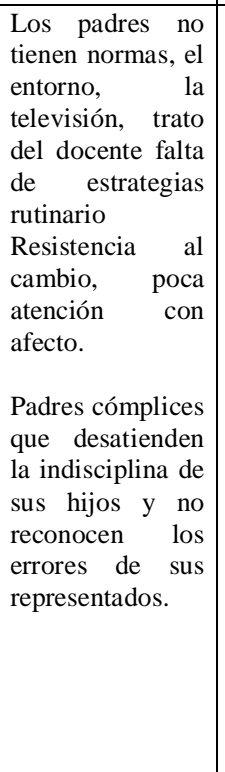 & 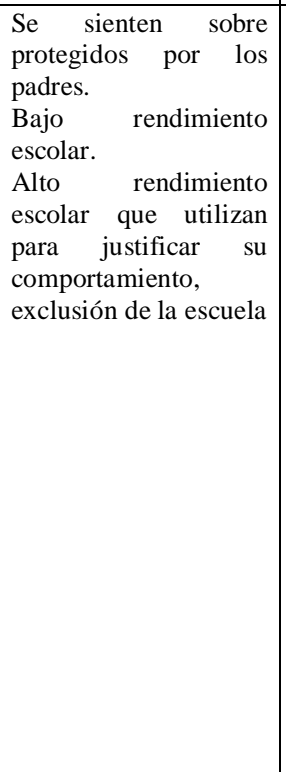 & 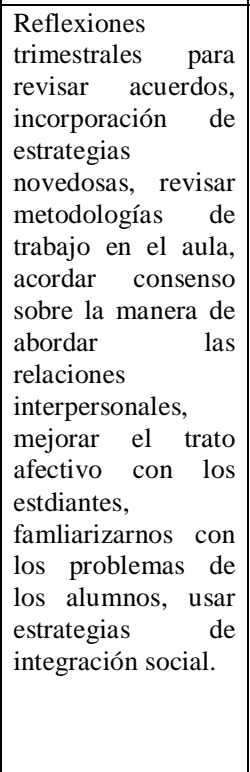 & 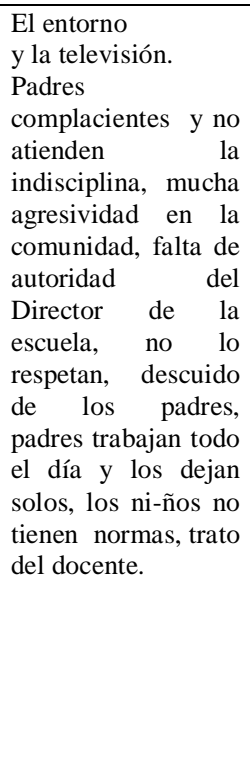 & \begin{tabular}{|l|} 
Distanciamiento entre \\
docentes y padres y \\
representantes, \\
rivalidad entre los \\
actores, \\
descalificación. \\
Pérdida de autoridad, \\
inasistencia reiterada \\
de alumnos a la \\
escuela y de padres y \\
representantes a las \\
reuniones.
\end{tabular} & $\begin{array}{|lrr|}\text { Participar } & \text { en } & \text { la } \\
\text { toma } & & \text { de } \\
\text { decisiones, } & \\
\text { mejorar } & \text { el } & \text { trato } \\
\text { y comunica-ción } \\
\text { con los } & \text { niños } & \text { y } \\
\text { sus } & \text { padres, } \\
\text { convocar } & \text { a } & \text { los } \\
\text { padres } & \text { y } \\
\text { representantes } & \text { a } \\
\text { reuniones } & \\
\text { periódicas, } & \\
& \\
\end{array}$ & 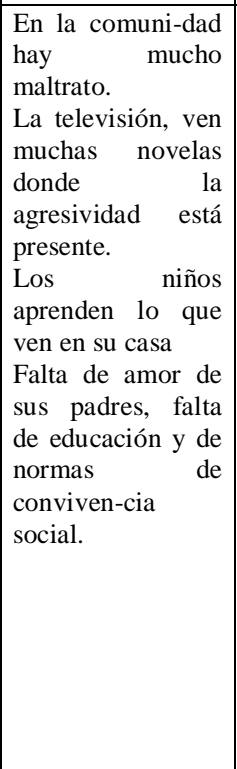 & $\begin{array}{l}\text { Exclusión de } \\
\text { los niños de } \\
\text { la escuela, } \\
\text { trato } \\
\text { inadecuado a } \\
\text { los niños, } \\
\text { deficiente } \\
\text { comunica- } \\
\text { ción con los } \\
\text { niños y sus } \\
\text { padres, } \\
\text { estrategias de } \\
\text { enseñanza y } \\
\text { aprendizaje } \\
\text { no acordes } \\
\text { con las } \\
\text { necesidades } \\
\text { de los niños, } \\
\text { niños } \\
\text { agresivos, } \\
\text { padres } \\
\text { irrespetuosos } \\
\text { y descalifica- } \\
\text { dores. }\end{array}$ & $\begin{array}{l}\text { Reflexiones trimestrales para } \\
\text { revisar los acuerdos, } \\
\text { adecuación de las } \\
\text { metodologías de trabajo, } \\
\text { consenso en cuanto a la forma } \\
\text { de abordar las relaciones con } \\
\text { los grupos, búsqueda de } \\
\text { soluciones, revisión de normas } \\
\text { y } \\
\text { Reglamentos.Insistir en el } \\
\text { logros de aprendizajes } \\
\text { significativos y el uso de } \\
\text { estrategias para el rescate de } \\
\text { los valores, discutir y conocer } \\
\text { la LOPNA, } \\
\text { favorecer el respeto, amistad, } \\
\text { el compartir, el fomentar la } \\
\text { diálogo, } \\
\text { responsabilidad, revisar y } \\
\text { mantener acuerdos, reinsertar } \\
\text { los estudiantes excluidos, hacer } \\
\text { seguimiento de los alumnos, } \\
\text { crear la escuela para padres. }\end{array}$ \\
\hline
\end{tabular}




\begin{tabular}{|c|c|c|c|c|c|c|c|c|c|}
\hline $\begin{array}{l}\text { Padres y } \\
\text { Represen- } \\
\text { tantes }\end{array}$ & $\begin{array}{l}\text { No hacen caso, } \\
\text { son muy necios, } \\
\text { pelean mucho, } \\
\text { no quieren ir a la } \\
\text { escuela, se } \\
\text { burlan de mi, se } \\
\text { van a la calle sin } \\
\text { permiso, cuando } \\
\text { toma cosas o } \\
\text { dinero escondido } \\
\text { me da mucha } \\
\text { rabia. }\end{array}$ & $\begin{array}{l}\text { Irrespeto, rabia rencor } \\
\text { rebeldía desobediencia }\end{array}$ & 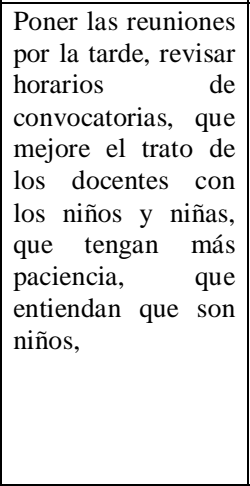 & $\begin{array}{l}\text { pelean mucho, } \\
\text { no les gusta ir a la } \\
\text { escuela, los } \\
\text { muchachos } \\
\text { no me respetan } \\
\text { Cuando roban } \\
\text { alguna cosa y no me } \\
\text { dicen nada, cuando } \\
\text { llego muy cansada a } \\
\text { la casa, tengo poca } \\
\text { paciencia, cuando } \\
\text { no hacen las tareas. }\end{array}$ & 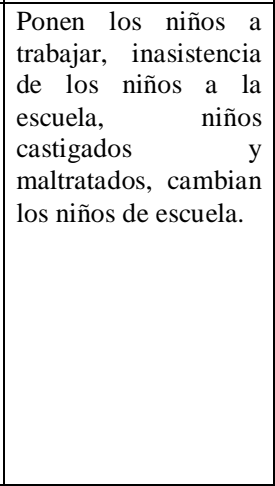 & $\begin{array}{|lr|}\text { Reuniones } & \text { y } \\
\text { convocatorias } & \text { en } \\
\text { horarios de } & \text { la } \\
\text { tarde, no en } & \text { en } \\
\text { horas tempranas, } \\
\text { que los docentes } \\
\text { reciban talleres } \\
\text { sobre maltrato } \\
\text { escolar, asesorías } \\
\text { con la LOPNA. } \\
\end{array}$ & $\begin{array}{l}\text { No hacen caso, } \\
\text { pelean mucho } \\
\text { no quieren ir a la } \\
\text { escuela } \\
\text { no salen sin } \\
\text { permiso, los } \\
\text { maestros no los } \\
\text { tratan con amor y } \\
\text { cariño, trabajo } \\
\text { mucho, todo el día } \\
\text { y estoy cansada, } \\
\text { que los docentes } \\
\text { no sean tan } \\
\text { autoritarios. }\end{array}$ & $\begin{array}{l}\text { Retiro de los } \\
\text { niños de la } \\
\text { escuela, niños } \\
\text { trabajando en } \\
\text { edad escolar, } \\
\text { agresión e } \\
\text { insulto de } \\
\text { docentes y } \\
\text { directivos, } \\
\text { castigo físico, } \\
\text { verbal y y } \\
\text { psicológi-co } \\
\text { de los niños }\end{array}$ & 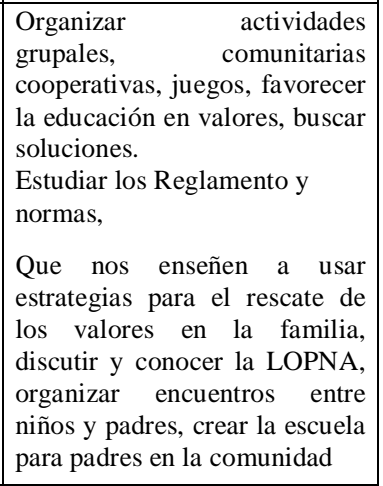 \\
\hline
\end{tabular}

Las Estrategias de Mediación utilizadas fueron las analizadas en la revisión teórica y las sugeridas por los actores, tal como se presentan en el Cuadro 3.

Cuadro 3 Estrategias de Mediación utilizadas en cada una de las etapas de la investigación en las tres Unidades Educativas:

\begin{tabular}{|c|c|c|c|c|}
\hline \multirow[b]{2}{*}{ Etapas } & \multicolumn{4}{|c|}{ Estrategias de Mediación } \\
\hline & $\begin{array}{l}\text { Círculos de } \\
\text { Calidad }\end{array}$ & $\begin{array}{l}\text { Ayuda entre } \\
\text { iguales }\end{array}$ & \begin{tabular}{|c|}
$\begin{array}{c}\text { Desarrollo de la } \\
\text { acertividad para } \\
\text { víctimas }\end{array}$ \\
\end{tabular} & $\begin{array}{c}\text { Desarrollo de la } \\
\text { empatía }\end{array}$ \\
\hline $\begin{array}{l}\text { I. Diagnóstico } \\
\text { comunitario de } \\
\text { las escuelas. }\end{array}$ & $\begin{array}{lr}\text { Reuniones, } & \\
\text { visitas } & y \\
\text { asistencia al } & \mathrm{I} \\
\text { encuentro } & \\
\text { "Corazones } & \text { y } \\
\text { manos unidas por } \\
\text { la convivencia } & \text { y } \\
\text { la paz". }\end{array}$ & 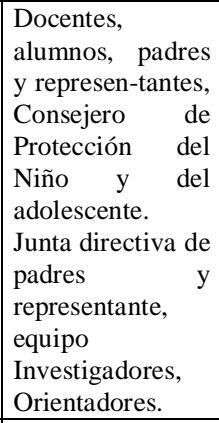 & $\begin{array}{l}\text { Atención de casos por } \\
\text { el consejero } \\
\text { Protección del niño y } \\
\text { del adolescente y } \\
\text { equipo de } \\
\text { orientadores. }\end{array}$ & $\begin{array}{l}\text { Sensibilización. } \\
\text { Elaboración de } \\
\text { carteleras y mensajes } \\
\text { alusi-vos al amor y la } \\
\text { amistad, encuen-tros, } \\
\text { actividades deportivas y } \\
\text { culturales, almuerzos } \\
\text { comunitarios. }\end{array}$ \\
\hline $\begin{array}{c}\text { II: } \\
\text { Formulación } \\
\text { del Plan. }\end{array}$ & $\begin{array}{l}\text { Jornadas de } \\
\text { lectura, análisis y } \\
\text { reflexión, } \\
\text { reuniones, } \\
\text { encuentros, } \\
\text { convivencias. }\end{array}$ & 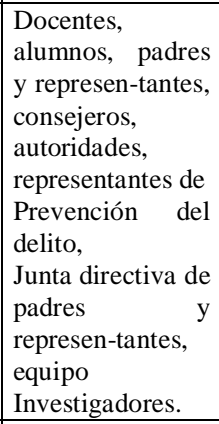 & $\begin{array}{l}\text { Atención de casos por } \\
\text { los consejeros, } \\
\text { Protección del niño y } \\
\text { del adolescente, } \\
\text { Prevención del delito, } \\
\text { Orientadora de la } \\
\text { institución. }\end{array}$ & $\begin{array}{llr}\text { Participación } & \text { de } \\
\text { alumnos, padres } & \text { y } \\
\text { representantes, en } & \text { las } \\
\text { dinámicas } & \text { de } \\
\text { sensibilización r } & y \\
\text { elaboración del plan de } \\
\text { acción. }\end{array}$ \\
\hline III: Ejecución & Docentes. & Se organizaron & Se atienden a los & Se realizaron \\
\hline
\end{tabular}




\begin{tabular}{|c|c|c|c|c|}
\hline del plan. & $\begin{array}{l}\text { Alumnos. } \\
\text { Padres y } \\
\text { representantes. } \\
\text { Investigadores. } \\
\text { Participan en las } \\
\text { diferentes } \\
\text { actividades }\end{array}$ & $\begin{array}{l}\text { gru-pos de niños } \\
\text { para ayudar a sus } \\
\text { compa-ñeros a } \\
\text { compartir las } \\
\text { actividades } \\
\text { escolares dentro } \\
\text { y fuera del aula. } \\
\text { De igual forma, } \\
\text { grupos de } \\
\text { docentes para } \\
\text { discutir, revisar y } \\
\text { reflexionar } \\
\text { crítica-mente } \\
\text { sobre ra } \\
\text { problemática. Se } \\
\text { atendieron las } \\
\text { familias y se } \\
\text { designaron } \\
\text { padres para } \\
\text { ayudar a los } \\
\text { otros. }\end{array}$ & $\begin{array}{|lrr|}\text { padres, } & \text { docentes } & \text { y } \\
\text { alumnos } & \text { por } & \text { la } \\
\text { docente de } & 2^{\circ} \text { grado; } \\
\text { orientadora } & \text { de } & \text { la } \\
\text { institución y } & \text { los } \\
\text { investigadores. } & \end{array}$ & $\begin{array}{l}\text { juegos, activida-des de } \\
\text { dramati-zación como el } \\
\text { pesebre viviente, pinta } \\
\text { cuentos, día de la } \\
\text { bandera, día del árbol, } \\
\text { día de la madre, día del } \\
\text { padre, se publi-caron } \\
\text { los traba-jos y dibujos } \\
\text { en las carteleras. }\end{array}$ \\
\hline
\end{tabular}

El Cuadro 4, resume el conjunto de dimensiones que surgieron del abordaje empírico del estudio, así como las categorías y subcategorías que emergieron del análisis de la información recabada.

\section{Cuadro 4: Dimensión, Categorías y Subcategorías emergieron de la Investigación}

\begin{tabular}{|c|c|c|}
\hline Dimensión & Categorías & $\begin{array}{c}\text { Subcategorías } \\
\end{array}$ \\
\hline \multirow{2}{*}{$\begin{array}{l}\text { Comportamientos } \\
\text { Agresivos: expresión } \\
\text { externa de violencia } \\
\text { física verbal y } \\
\text { psicológica persistente, } \\
\text { reiterativa, contra la } \\
\text { propiedad, la familia, } \\
\text { compañeros y demás } \\
\text { individuos, que produce } \\
\text { daño y es contraria a las } \\
\text { normas sociales }\end{array}$} & $\begin{array}{l}\text { Violencia verbal: } \\
\text { Emisión de expresiones } \\
\text { verbales hacia otra persona } \\
\text { en tono de voz alto o bajo } \\
\text { que por su contenido, } \\
\text { produce efectos visibles en el } \\
\text { otro. }\end{array}$ & $\begin{array}{l}\text { Gritos: Considerados como formas de comunicación, } \\
\text { "palabras obscenas, tono de voz muy alto, ofensas } \\
\text { burlas, discusiones". } \\
\text { Sobrenombres: calificativo asignado por los padres } \\
\text { y demás integrantes de la comunidad a los niños, } \\
\text { niñas, adolescentes. Ejemplos, "La chiqui, la chiri, } \\
\text { caqui, boca de bagre, ñoño, tacupay, chicharra, } \\
\text { amarillo, lolo, coneja, ratona, miyo, gorda, piqui”" } \\
\text { Gestos despectivos: Acciones que se expresan a } \\
\text { través de gestos corporales (miradas, expresiones } \\
\text { faciales). "el maestro mira muy feo a uno". }\end{array}$ \\
\hline & $\begin{array}{l}\text { Violencia Física: } \\
\text { Uso excesivo de la fuerza } \\
\text { física que tiene la intención } \\
\text { de causar daño. }\end{array}$ & $\begin{array}{l}\text { Golpes: Maltrato físico como forma de corregir una } \\
\text { situación. "La única manera que tengo de que me } \\
\text { haga caso es pegándole" Jalar las orejas y pelo } \\
\text { pellizcar" }\end{array}$ \\
\hline
\end{tabular}

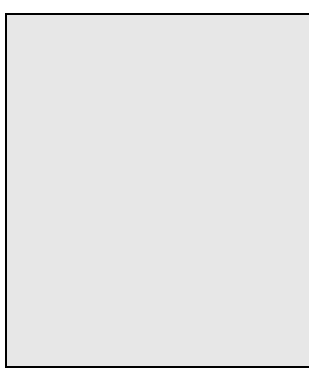

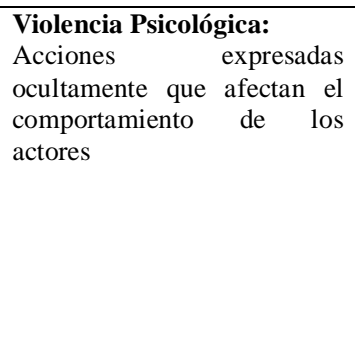

Autoritarismo: Mecanismo ejercido por los padres, docentes y directivos para lograr controlar la disciplina de los educandos maltrato u otro tipo de acción degradante que produce en los actores trauma en su estructura de la personalidad generando personas carentes de afecto y con problemas graves de comunicación." Le tengo miedo a mi maestra me va a mandar a la dirección no revisa mi tarea, a mi compañero le tengo miedo por que es más grande que yo", "Yo soy la máxima autoridad si no cumplen
se les levanta un acta"

Los resultados obtenidos, permiten destacar que fueron logrados todos los objetivos propuestas. De igual manera, se debe indicar que se realizaron el $100 \%$ de las actividades planificadas, las cuales facilitaron a los padres y representantes, docentes y estudiantes, comportamientos agresivos (Ver Cuadro 5).

Cuadro 5 . Resultados obtenidos según la estrategia de interacción social aplicada.

\begin{tabular}{|c|c|c|}
\hline $\begin{array}{c}\text { Estrategi } \\
\text { as }\end{array}$ & Actividades & Resultados obtenidos \\
\hline $\begin{array}{l}\text { Círculos } \\
\text { de } \\
\text { Calidad }\end{array}$ & $\begin{array}{l}\text { Reuniones cada } 15 \text { días, entre los actores y } \\
\text { grupo de investigadores. } \\
\text { I Encuentro “Corazones y manos unidos por la } \\
\text { convivencia y la paz”. } \\
\text { I y II Jornada de análisis y reflexión. }\end{array}$ & $\begin{array}{l}\text { Mejorar el intercambio de ideas y la } \\
\text { comunicación entre los actores, } \\
\text { fortalecimiento de la participación, } \\
\text { formalización de los compromisos, cambios } \\
\text { de comportamientos de los actores } \\
\text { volviéndose más sensibles y preocupados. } \\
\text { Niños entusiastas y dispuestos a participar en } \\
\text { diferentes actividades }\end{array}$ \\
\hline $\begin{array}{l}\text { Ayuda } \\
\text { entre } \\
\text { iguales }\end{array}$ & $\begin{array}{l}\text { Designación de la comisión de disciplina, } \\
\text { comisiones de guardia, selección de estudiantes } \\
\text { y padres y representantes colaboradores. } \\
\text { Elaboración de horarios de atención individual } \\
\text { y colectiva. Organización de grupos de niños } \\
\text { para ayudar a sus compañeros; de padres para } \\
\text { ayudar a otros adultos; y de docentes, para } \\
\text { reflexionar críticamente sobre la problemática. }\end{array}$ & $\begin{array}{l}\text { Mejoramiento de los comportamientos } \\
\text { agresivos a través de los recreos dirigidos. } \\
\text { Relación interpersonal e intergrupales } \\
\text { satisfactorias. } \\
\text { Disminuyó la presencia de niños agresivos en } \\
\text { la dirección. } \\
\text { Establecimiento de normas en el comedor a } \\
\text { través de la ayuda mutua de los alumnos de } \\
\text { grado superiores. } \\
\text { Acompañamiento pedagógico entre alumno, } \\
\text { padre y representante en las actividades } \\
\text { dentro y fuera del aula. }\end{array}$ \\
\hline
\end{tabular}




\begin{tabular}{|c|c|c|}
\hline $\begin{array}{l}\text { Desarrol } \\
\text { lo de la } \\
\text { asertivid } \\
\text { ad para } \\
\text { víctimas }\end{array}$ & $\begin{array}{l}\text { Nombramiento democrático de la coordinadora } \\
\text { de la red escolar del consejo de protección al } \\
\text { niño y al adolescente. }\end{array}$ & $\begin{array}{l}\text { Atención individualizada, por previa cita, para } \\
\text { padres, alumnos y docentes. } \\
\text { Atención de dieciséis familias de la } \\
\text { comunidad, creando confianza de los actores } \\
\text { en el quehacer educativo. } \\
\text { Acuerdo conciliatorio entre los alumnos } \\
\text { involucrados en las situaciones de } \\
\text { comportamiento inadecuado. } \\
\text { Canalización de los casos reincidentes ( no } \\
\text { son enviados a la dirección sino al } \\
\text { orientador). Incorporación de los entes } \\
\text { gubernamentales: Prevención del delito y } \\
\text { consejo de Protección del niño y el } \\
\text { adolescente. }\end{array}$ \\
\hline $\begin{array}{l}\text { Desarrol } \\
\text { lo de la } \\
\text { empatía } \\
\text { para } \\
\text { agresore } \\
\quad \text { s }\end{array}$ & $\begin{array}{l}\text { Fomento de valores religiosos entre los } \\
\text { alumnos a través de catequesis, la coronación } \\
\text { de la virgen, las comuniones. } \\
\text { Celebración de efemérides y fechas especiales } \\
\text { (festivales y encuentros deportivos). }\end{array}$ & $\begin{array}{l}\text { Incorporación de docentes padres y } \\
\text { representantes a las actividades religiosas } \\
\text { programadas. } \\
\text { Sensibilización de los actores del quehacer } \\
\text { educativo a través de dramatizaciones, } \\
\text { lecturas, reflexión y mensajes en el patio de } \\
\text { formación. } \\
\text { Participación de quince niños en la primera } \\
\text { comunión. } \\
\text { Fortalecimiento de los lazos de } \\
\text { compañerismo, familiares y } \\
\text { sociales.Integración escuela - comunidad. }\end{array}$ \\
\hline
\end{tabular}

\section{HALLAZGOS}

$>\quad$ Los comportamientos agresivos presentes en los actores sociales de las Unidades Educativas “Emperatriz de Aguero”, “Los Cerritos” y Cerro Pelón, 1ra etapa de Educación Básica, fueron de tres tipos: verbales, físicos y psicológicos, y no presentaron diferencias entre escuelas.

Entre los factores que favorecen el comportamiento agresivo y afectan el proceso enseñanza aprendizaje en las Unidades Educativas se encuentran: el entorno, los medios de comunicación, falta de estrategias de mediación, la formación y el trato recibido en el hogar, la indiferencia de los padres y docentes, el desconocimiento y aplicación de la normativa vigente.
Las necesidades de capacitación y formación planteadas por los docentes, relacionadas con el comportamiento agresivo en la escuela, fueron: talleres y cursos sobre uso de estrategias, relaciones interpersonales, problemas de conducta, agresividad y aprendizaje.

Las necesidades educativas sobre comportamiento agresivo presentes en padres y representantes de la escuela fueron: talleres de relaciones familiares, relaciones interpersonales, valores, cultura y tradiciones, escuela de familia. También sugirieron la atención urgente de especialistas en el tema, especialmente de psicólogos.

$>\quad$ La Interacción Social como estrategia disminuyó el comportamiento agresivo en estudiantes, docentes, padres y representantes de las Unidades Educativas.

$>\quad$ Las Estrategias de Interacción Social desarrolladas han producido una mejora significativa del comportamiento de los niños y niñas de la 1era Etapa. No obstante, será necesario dar continuidad al trabajo desarrollado para lograr que se consolide el logro obtenido.

$>\quad$ Los docentes que participaron en el estudio han coincidido en mantener su compromiso de minimizar los comportamientos agresivos en la escuela.

Los encuentros de reflexión y organización participativa de las actividades, incidió positivamente en la actitud de los docentes, alumnos, padres y representantes, quienes demostraron cambios significativos en su comportamiento.

Las relaciones interpersonales entre docentes y alumnos mejoraron notablemente, situación que se pudo observar al verlos actuar .de manera disciplinada, tratando de mantener en equilibrio armónico.

El personal directivo de las tres Unidades Educativas asumieron una actitud colaboradora, flexible y comunicativa.

$>\quad$ La mayoría de los representantes demostraron disposición de participar y de incorporarse a las diferentes actividades; y, los docentes asumieron su responsabilidad de canalizar las situaciones de agresividad que se presentan en el aula o la escuela, involucrando a los padres en la solución de la situación 
Se evidenció la presencia de un alto porcentaje de niños con carencia de afecto familiar, apoyo y reconocimiento, volcando estas carencias en el afecto de los docentes, personal obrero y administrativo de las escuelas.

\section{REFERENCIAS}

Bandura, A., y Otros (1981). Comportamientos Conductuales de los seres. Material mimeografiado.

Bisquerrea, R. (2000). Educación Emocional y Bienestar. España: Editorial Praxis.

Dorsch (1994). Diccionario de Psicología. Barcelona: Editorial

Gessem, W. (2001). Las Emociones. [Revista en línea]- 5 (3). Disponible: www.psicosalud.com [Consulta: 2003; Agosto 10].

Gutiérrez, (1992). Manual de Psiquiatría. Mc Graw Hill Interamericana. Herder.

Gispert, (1995). Pedagogía moderna y conducta. Vol. III. Barcelona: Bruguera.

Goleman, D. (1996). La Inteligencia Emocional. Buenos Aires: Editorial Javier Vergara S.A.

Ortega y Mora. (2000). La Convivencia Escolar qué es y cómo abordarla. Sevilla: Conserjería de Educación y Ciencias de la Junta de Andalucía.

Ortega, Del Rey y Mora. (2001). Violencia entre iguales. Conceptos y etiquetas verbales que definen el fenómeno del maltrato entre iguales. afectivo y actitudinal . Revista Ínter universitaria de formación del Profesorado, 41.

Pérez, G. (1990). Investigación Cualitativa. Retos e Interrogantes. I métodos. Editorial La Muralla, s.a.

Pérez, J. (1993). Comportamientos agresivos y las relaciones personales. México. Editorial Limusa.

Rogers, (1984). Libertad y creatividad en educación. Madrid: Editorial Libertador. Barquisimeto.

Rojas (1996). Luis Rojas Marco y la Violencia Juvenil. [Documento en línea]: Disponible: ad.org.ved/programa. [Consulta: 2003, agosto $10]$.

Sequera, J. (2000). Propuesta de un Programa de capacitación dirigido a docentes de la Primera y Segunda Etapa de Educación Básica para la orientación e incremento del autocontrol emocional de los alumnos. Tesis de Maestría no publicada. Universidad Pedagógica Experimental Libertador. Barquisimeto.

Smith, J. (1993). [Revista en línea] 5(3). Disponible: http://www.Edgow/data-bases/EricDigist/ED397990.btml. 